\title{
Comment
}

Neuro epidemiology

Neuroepidemiology 2012;38:120-121

DOI: $10.1159 / 000336110$

\section{Carotid Artery Disease in Sub-Saharan Africa: A Marker of Epidemiological and Stroke Transition}

\author{
Myles D. Connor \\ Division of Clinical Neurosciences, University of Edinburgh, \\ Edinburgh, and Department of Neurology, NHS Fife, \\ Dunfermline, UK; School of Public Health, University of the \\ Witwatersrand, Johannesburg, South Africa
}

Over the past four decades, stroke incidence has increased by over $100 \%$ in developing (low- and middle-income) countries, while it has declined in high-income countries [1]. Although epidemiological data from Sub-Saharan Africa (SSA) are limited, indications are that stroke burden is increasing in this developing region as elsewhere $[1,2]$. The increase in stroke burden in developing regions reflects an epidemiological transition, caused largely by both increasing population age and prevalence of stroke risk factors [3]. A little recognised aspect of this transition is the changing profile or nature of stroke that occurs during this transition [4]. As populations move through the stages of transition, in theory at least, the causes and pathological type of stroke change. Early in the transition, hypertension is the dominant risk factor resulting in a higher proportion of cerebral haemorrhage than is found in populations later in the transition. Atherosclerosis, particularly extracranial atherosclerotic carotid artery disease, is more common in populations in later stages in the transition than in populations early in transition, reflecting the increasing importance of poor diet and high cholesterol levels in the stroke risk factor profile of higher income populations. If this is indeed the case, then populations living in low- to middle-income Sub-Saharan countries, currently in stage 1 or 2 of the transition, should have little extracranial atherosclerotic disease.

Until recently there have been almost no community-based stroke epidemiological data for SSA [1,2]. The best available evidence of the burden and nature of stroke in a population comes from community-based stroke incidence studies, fulfilling as many of the established 'ideal' criteria as possible [5]. The recent Tanzanian Stroke Incidence Project (TSIP) fulfilled many though not all these criteria, and provided much needed communitybased incidence data for the region [6]. In the December 2011 issue of Neuroepidemiology, the TSIP team describe the proportion of their incident stroke cases from the rural Hai district in Tanzania with carotid artery stenosis [7]. A consultant radiologist used duplex ultrasound to assess carotid stenosis in 56 of 132 incident stroke cases. They only included patients presenting with carotid territory strokes, and 22 patients died prior to assessment.

Only one of the 56 patients assessed, a 56-year-old non-smoking farmer with treated hypertension, had mild internal carotid artery stenosis (50\%). She did not have any other evidence of extracranial atherosclerotic disease or a significant medical history. None of the stroke survivors was on lipid-lowering therapy, roughly $8 \%$ ( 8 of 101 patients with valid data) had diabetes mellitus, and mean blood pressure was high (over $150 \mathrm{~mm} \mathrm{Hg}$ systolic and $95 \mathrm{~mm} \mathrm{Hg}$ diastolic). The authors conclude that carotid artery stenosis was uncommon in this cohort of rural Sub-Saharan Africans with previous stroke.

The study has several limitations. Probably the most notable is the small number of patients assessed. Only consecutive patients during the last 18 months of the study in the Hai (rural) site were included due to resource limitations. Although one of the strengths of the TSIP study was the thorough ascertainment and assessment of patients that died using verbal autopsy, a large proportion of patients died prior to assessment. Both ischaemic strokes (33 of 38 patients scanned within 15 days of onset) and cerebral haemorrhages were included; and as carotid stenosis is not a risk factor for cerebral haemorrhage, this may have reduced the proportion of patients with carotid stenosis. However, community-based stroke incidence studies are challenging in this low-resourced setting, and this is the first study to assess carotid artery disease in community-based SSA stroke patients.

The finding that carotid artery stenosis is uncommon in stroke patients is in keeping with the results of an urban hospital-based stroke study from South Africa. None of the 141 black patients with ischaemic stroke had evidence of atherosclerotic carotid artery disease, though investigations were limited [8]. Previous hospital-based stroke studies of black stroke patients from South Africa and Zimbabwe produced similar findings [9-11].

Carotid artery disease appears to be uncommon in stroke patients in SSA, though this is likely to change as the population advances through the epidemiologic transition. Carotid artery disease is as common in African-American stroke patients as it is in Hispanics and whites, and as the burden and profile of stroke risk factors change in SSA, so it is likely that carotid artery disease will increase without adequate risk factor prevention [12]. Unfortunately, health care resources are limited in SSA and a pragmatic approach is required. Feigin and Krishnamurthi [13] have recently argued compellingly for developing countries to tailor high risk and population-based risk factor prevention based on their stage in the transition. In SSA, hypertension is the predominant risk factor for stroke and resources should be aimed at prevention and control of blood pressure, while keeping an eye on emerging atherosclerotic disease such as carotid stenosis.

\section{KARGER}

Fax +4161306 1234

E-Mail karger@karger.ch

www.karger.com
(C) 2012 S. Karger AG, Basel

$0251-5350 / 12 / 0382-0120 \$ 38.00 / 0$

Accessible online at:

www.karger.com/ned 


\section{References}

1 Feigin VL, Lawes CM, Bennett DA, Barker-Collo SL, Parag V: Worldwide stroke incidence and early case fatality reported in 56 populationbased studies: a systematic review. Lancet Neurol 2009;8:355-369.

-2 Connor MD, Walker R, Modi G, Warlow CP: Burden of stroke in black populations in sub-Saharan Africa. Lancet Neurol 2007;6:269-278.

-3 Yusuf S, Reddy S, Ounpuu S, Anand S: Global burden of cardiovascular diseases. II: Variations in cardiovascular disease by specific ethnic groups and geographic regions and prevention strategies. Circulation 2001;104:2855-2864.

4 Bonita R: Stroke prevention: a global perspective; in Norris J, Hachinski V (eds): Stroke Prevention. Oxford, Oxford University Press, 2001.

5 Feigin V, Hoorn SV: How to study stroke incidence. Lancet 2004;363: 1920.

-6 Walker R, Whiting D, Unwin N, Mugusi F, Swai M, Aris E, Jusabani A, Kabadi G, Gray WK, Lewanga M, Alberti G: Stroke incidence in rural and urban Tanzania: a prospective, community-based study. Lancet Neurol 2010;9:786-792.

7 Jusabani A, Gray WK, Swai M, Walker R: Post-stroke carotid ultrasound findings from an incident Tanzanian population. Neuroepidemiology 2011;37:245-248.

8 Connor MD, Modi G, Warlow CP: Differences in the nature of stroke in a multiethnic urban South African population: the Johannesburg hospital stroke register. Stroke 2009;40:355-362.
-9 Matenga J, Kitai I, Levy L: Strokes among black people in Harare, Zimbabwe: results of computed tomography and associated risk factors. $\mathrm{Br}$ Med J (Clin Res Ed) 1986;292:1649-1651.

10 Rosman KD: The epidemiology of stroke in an urban black population. Stroke 1986;17:667-669.

11 Joubert J: The MEDUNSA Stroke Data Bank. An analysis of 304 patients seen between 1986 and 1987. S Afr Med J 1991;80:567-570.

12 White H, Boden-Albala B, Wang C, Elkind MS, Rundek T, Wright CB, Sacco RL: Ischemic stroke subtype incidence among whites, blacks, and Hispanics: the Northern Manhattan Study. Circulation 2005;111:13271331.

13 Feigin VL, Krishnamurthi R: Stroke prevention in the developing world. Stroke 2011;42:3655-3658.

Myles D. Connor

Bramwell Dott Building, Western General Hospital Crewe Road

Edinburgh EH4 2XU (UK)

E-Mailmconnor@staffmail.ed.ac.uk 